\title{
Chronic Inflammatory Mediators Induced Malignant Changes in Inflammatory Microenvironment of Oral Potentialy Malignant Conditions - An Emerging Concept
}

\author{
T.G. Shrihari
}

\section{Department of Oral Medicine and Oncology, Krishna Devaraya College of Dental Sciences and Hospital, Bangalore -562157, Karnataka, India}

\begin{abstract}
Potentially malignant conditions of the oral cavity are potential threat to mankind because of its malignant changes later. Oral potentially malignant conditions are chronic inflammatory mucocutaneous disorder affecting oral mucosa. Inflammatory mediators induced by chronic inflammatory microenvironment of premalignant conditions are cytokines, chemokines, growth factors, proteolytic enzymes, released by inflammatory cells such as macrophages, lymphocytes, neutrophils, mast cells, activate transcriptional factors such as NF-kB, STAT-3 and HIF-1 $\alpha$, promotes cell proliferation, angiogenesis, tumor promotion, resistant to apoptosis, epithelial to mesenchymal transition, induced invasion and metastasis. Carcinoma associated fibroblasts in tumor microenvironment originated by activated fibroblasts secretes cytokines and growth factors promotes tumor progression by cell proliferation, angiogenesis, cell survival, genomic instability, invasion and metastasis. Myeloid derived suppressor cells are specialized heterogeneous immature myeloid progenitor cells that are dendritic cells, macrophages, granulocytes produced upon chronic inflammatory mediators. These cells responsible for immune evasion, immunosuppression and tumor progression by various mechanisms and interaction with other immune cells, activating transcriptional factors such as NF-kB and STAT-3. This article describe about roles of chronic inflammatory cells and their mediators in inflammatory microenvironment of premalignant conditions bring about malignant changes in oral sub mucous fibrosis and oral lichen planus.
\end{abstract}

Keywords: MDSC(Myeloid derived suppressor cells), VEGF(Vascular endothelial growth factor), TNF(Tumor necrosis factor), TGF(Transforming growth factor), Oral Submucous fibrosis, Oral Lichen planus, NF-kB, STAT3,Carcinoma associated fibroblast, Tumor associated macrophage.

\section{INTRODUCTION}

Oral premalignant conditions of oral cavity are also called as oral potentially malignant conditions are chronic inflammatory diseases affecting oral mucous membrane and skin (eg; Lichen planus, oral sub mucous fibrosis). It is a generalised alteration in condition of oral mucosa in which cancer is most likely to occur. Chronic inflammatory mediators in oral potentially malignant conditions, which are responsible for pro- tumoral activity further leads to cancer [1, 2]. Oral submucous fibrosis has a highest rate of malignant potential mainly due to arecanut chewing habit, genetic and infectious agents in some studies, affects oral cavity, pharynx, and upper $1 / 3$ rd of esophagus leading to dysphagia and progressive limited mouth opening due to increased production of collagen by fibroblasts. IL-1, TGF- $\beta$, PDGF, bFGF, cytokines and growth factors stimulate collagen production. $\mathrm{IL}-1$ and TNF- $\alpha$ induced NF-KB transcription factor activation, IL-6 and EGF activates STAT3 transcriptional factor induced by fibroblasts mediated cytokines IL-1, IL-6, IL-8 and TNF- $\alpha$ bring

*Address correspondence to this author at the Department of Oral Medicine and Oncology, Krishna Devaraya College of Dental Sciences and Hospital, Bangalore -562157, Karnataka, India; Tel: 91-9844386188;

E-mail: drshrihariomr@gmail.com about cell proliferation, angiogenesis, resistant to apoptosis, invasion and metastasis.

Oral lichen planus is a chronic inflammatory disease of oral mucosa the inflammatory pattern display hallmark of a T-cell mediated disease. Thought to have an autoimmune etiology but no antigen or autoantibodies identified, many studies have showed that it is associated with psychological stress. Lymphocytic and macrophage infiltration in the basal lamina of epithelium is a typical feature, producing inflammatory mediators such as IL-6, TNF- $\alpha, \mathrm{IL}-1$ and IL-8 pro-inflammatory cytokines play a role in malignant transformation [3].

Infectious agents such as microbial stimuli or cellular constituents released upon cell injury and cell death such as (HSp-70 in lichen planus) known as PAMP(Pathogen associated molecular patterns) and DAMP(Damage associated molecular patterns) are recognized by pattern recognition receptors(PRR) belongs to the family of TLR(Toll like receptors) activates innate immunity, results in upregulation of MHC class1 and 11, costimulatory molecules, cytokines, growth factors and chemokines results in activation of key transcription factors such as NF-kB and STAT-3 involved in tumor progression [3,41]. 


\section{INFLAMMATORY MICROENVIRONMENT OF ORAL} POTENTIALY MALIGNANT CONDITIONS

The inflammatory mediators in chronic inflammatory microenvironment of oral potentialy malignant conditions are IL -1 , prostaglandin E2, $\mathrm{T}$ lymphocytes, mast cells, TNF- $\alpha$, TGF- $\beta$, macrophages, and matrix metalloproteases. Inflammatory cytokines rich microenvironment associated with oral potentially malignant conditions may particularly favorable for tumor promotion [4-8]. Pro- inflammatory cytokine production of IL-1 leads to activation of prostaglandins mediated events via the action of the enzyme cyclooxygenase -2 (Cox-2) an arachidonic acid derivative (Figure 1).

\section{ROLE OF CHRONIC INFLAMMATORY MEDIATORS IN ORAL POTENTIALLY MALIGNANT CONDITIONS}

It has been evidenced that prostaglandins play a significant role in the regulation of local immune response by generation of myeloid derived suppressor cells, as well as carcinogen activation and tumor initiation [9]. Cellular degeneration by Sub epithelial infiltration of $\mathrm{T}$ - lymphocytes contributes to the local production of cytokines, which in turn stimulates production of reactive Oxygen species (ROS), reactive nitrogen intermediates (RNI) cause oxidative damage to the tissues. T helper (Th) cells may differentiate into two major subtypes with distinct cytokine profiles and functions in the immune system. Th1 cells typically produce IFN- $\mathrm{y}$ and TNF- $\alpha$, which are involved in macrophage activation and play a role in auto-immune diseases associated with chronic infections. The Th17 cytokine is a subset of CD4 T cells produce IL-17, induced by IL-23 pro-inflammatory cytokine is a major mediator of tissue inflammation involved in several autoimmune and inflammatory diseases, activate macrophages, which enhances $\mathrm{T}$ cell mediated reactions, inducing production of chemokine's and other pro-inflammatory cytokines such as IL-1 $\beta$, TNF- $\alpha$, IL-6 $[10,11]$. It has been shown to upregulate and/or synergize with local inflammatory mediators and promote extracellular matrix degradation through stimulating production of MMPs. IL-8 proinflammatory cytokine produced by epithelial cell in an early response of tissue damage, which together with TNF- $\alpha$ and histamine inflammatory mediators secreted by resident macrophages and mast cells allows extravasation of neutrophils to the site of injury results in initiation of inflammation [12].

Chemotactic cytokines are chemokines that involve in migratory and positioning of immune cells to the site of inflammation. Receptors of chemokine's are expressed on all leucocytes produced by stromal and tumor cells, facilitates tumor progression. Neutrophil recruitment is mediated by CXCL1, CXCL2, CXCL3, CXCL5, CXCL6, CXCL7, CXCL8. Recruitment of macrophages and other innate immune cells are by CCL2, CXCL12-CXCR4, CCL4, CCL5, MCP-1.

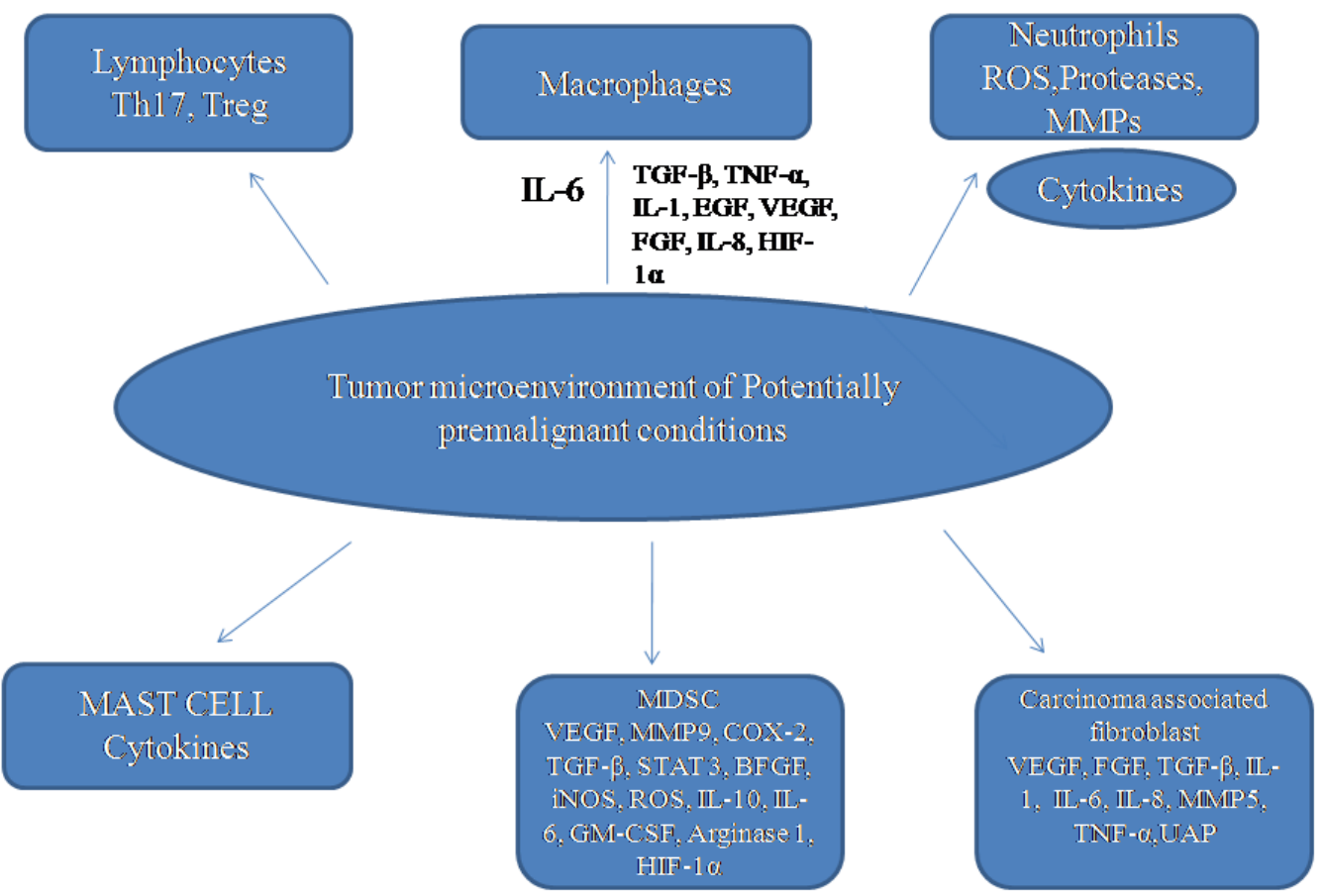

Figure 1: Chronic inflammatory mediators in inflammatory microenvironment of oral potentially premalignant conditions. 
Lymphocytes recruitment by CXCL12-CXCR4, CXCL9, CXCL10,CXCL11, CCR7-CCL21, CXCL19. XCR1 receptors for XCL1(Lymphotactin) expressed on oral cancer cells, keratinocytes and neutrophils, overexpressed on oral cancer cells and in metastatic deposits compared to normal cells on immunohistochemical analysis. Positive staining was seen in an oral potentially premalignant condition called lichen planus with immunological etiology. XCR1 stimulation led to increase in gelatinase MMP2 and MMP9 expression in cancer cells, involve in matrix remodeling and invasion in malignant disease.

Inflammatory factors promoting proliferation are TGF- $\beta$, FGF (Fibroblast growth factor), and EGF (epithelial growth factor). TGF- $\beta$ is synthesized by mast cells, macrophages, and lymphocytes as an inactive precursor, that is activated by proteases in an inflammatory environment. TGF- $\beta$ promotes mesenchymal cell proliferation and facilitates tumor invasion and metastasis [13, 14]. FGF and EGF are produced by activated macrophages, IL-6 is also produced by tumor associated macrophages, a proliferative factor in cancer, involved in cell proliferation, angiogenesis, and cell survival $[15,16]$. Cytokines(IL-8,IL-6,IL-1), Chemokine's (CCL2, CCL4,CCL5, CXCL1 and CXCL8), growth factors(GCSF, EGF, VEGF, TGF- $\beta$, GM-CSF) ligands trigger signaling cascades that activates NF-KB, STAT3 transcription factors, promotes cell proliferation, angiogenesis, resistant to apoptosis, epithelial to mesenchymal transition induced invasion and metastasis (Figure 2a, 2b, 2c) [17].

NF-kB is a master regulator of an immune response and important mediator of cell survival by inducing $\mathrm{BCL}-2$ and $\mathrm{Bcl}-\mathrm{XL}$ protein expression, which in turn triggers expression of pro -inflammatory cytokines, adhesion molecules, and enzymes such as cyclooxygenase 2, matrix metalloproteases 2,9 metalloproteases, iNOS and angiogenic factors favours cell proliferation, angiogenesis, immunosuppression, invasion and metastasis. NF-kB will have a P53 tumor suppressor gene antagonistic activity via expression of AID (Activation induced Cytidine Deaminase) enzyme leads to genomic instability, thereby helps in tumor progression by reducing apoptotic activity of cancer cells results in cancer cells survival. IL-6, EGF, FGF, HGF, PDGF, JAK (janus kinases), tyrosine kinases such as c-met and src activate STAT3 transcription factor work together with NF-KB a key transcription factor involved in chronic inflammation induced tumor initiation, promotion, and progression of oral cancer.
STAT3 transcription factor involved in cell proliferation by induced expression of cyclin $D$ and cell survival by $B C L-2$ and BCL-XL anti-apoptotic proteins [18, 19]. $\mathrm{P} 13 \mathrm{~K}$ is also recognized as the main mediator of cell survival in inflammatory microenvironment [20]. Chronic inflammatory cells in inflammatory microenvironment are myeloid derived suppressor cells, macrophages subtypes (M1 and M2), a TIE2expressing monocyte subset, mast cells, neutrophils, and $\mathrm{T}$ and $\mathrm{B}$ lymphocytes. These cells secrete chemokine's, prostaglandins, proteases and complement components that collectively bring about an exaggerated inflammatory state, promote cancer growth, angiogenesis, tissue invasion and metastasis [21].

Tumor associated macrophages are functionally and phenotypically divided into two subtypes are M1 phenotype or classically activated macrophages (by Th1 cytokines such as IFN- $\gamma$ ), secrete TNF- $\alpha$, IL-1, IL2, IL-6, IL-12 or IL-23 and M2 phenotype or alternatively activated (by Th2 cytokines such as IL-4, $\mathrm{IL}-13, \mathrm{IL}-10)$ in the tumor microenvironment. M1 macrophages shift towards M2 macrophages secrete TGF- $\beta$ and produce chemokine CCL22 that attracts Treg (Regulatory $T$ cell) cells. Regulatory $T$ cells (Tregs) are main subset of CD4 T cells, express CD25 and FOXP3 involved in immunosuppression by secreting IL-10 and TGF- $\beta$, suppressing the activity of natural killer (NK) cells, IFN-y, IL- 12 and cytotoxic Tcells, which is responsible for immunosuppressive activity and immune evasion. $T$ cell mediated immunosuppression by expression of PD-1 and CTLA4 receptors on its surface. M2 tumor associated macrophages promote cell proliferation (by IL-1 and IL6 cytokine production), angiogenesis (by secreting angiopoietins 1 and 2, HIF-1a, VEGF, GM- CSF, COX2 and EGF), invasion by secreting proteases (Cathepsin B and D,UPA, MMP -2, 9), Chronic inflammation(by secreting COX-2) and immunosuppression by (iNOS, COX-2, TGF- $\beta$, IL-10) [21-23]. Interleukin -8 released from the epithelial cells attracts the neutrophils to the inflammatory site in response to oncogenic stress, in tumor microenvironment of oral premalignant conditions. HIF$1 \alpha$ induced during hypoxic condition by tumor associated macrophages acts as a transcriptional factors for VEGF, IL-1 $\beta$, and IL-8 favors angiogenesis. Neutrophils are polarized from anti-tumor N1 to a protumoral N2 phenotype, this is regulated by TGF- $\beta$ induced arginase-1 expression [24, 25]. Neutrophils are recruited to the tumor micro-environment secrete 


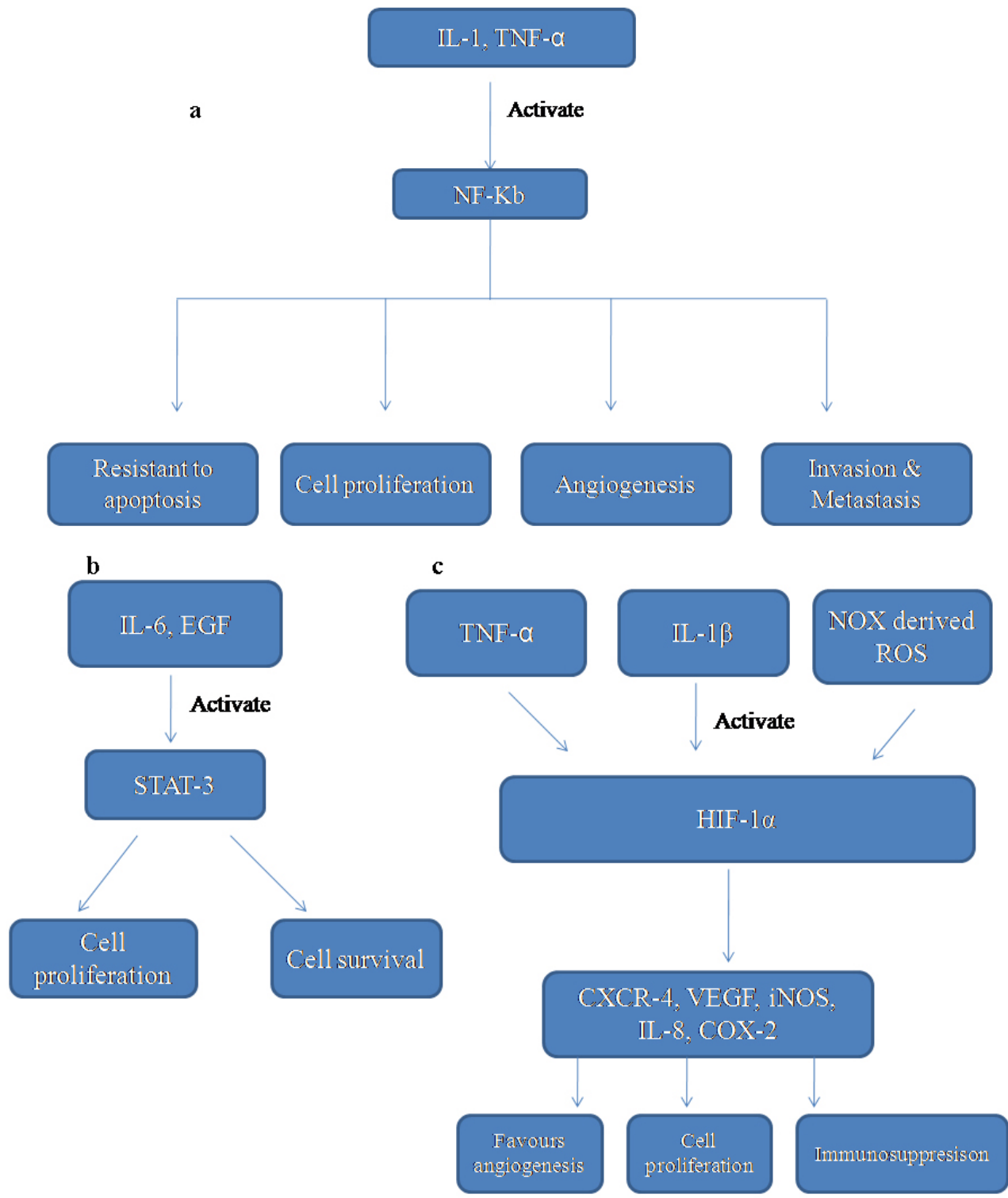

Figure 2: Transcription factors activated by inflammatory mediators involved in progression of cancer in potentially premalignant conditions of oral cavity.

prokinectin 2, MMP-9, induce neighbor cells to release VEGF to facilitate the arrival of tumor cells and proliferation by PDGF (Platelet Derived growth factor), thus helps in angiogenesis, tumor growth and metastasis.

B-Lymphocytes secretes IL-10 involved in immunosuppression known as Breg cells regulatory B cells. B-lymphocytes activate mast cells and myeloid cells promotes tumor progression. Mast cells brought to the tumor site by stem cell factor and other inflammatory chemo attractants secretes TNF- $\alpha, \mathrm{IL}-10$, IL-1, and IL-6 cytokines favor tumor growth, angiogenesis and metastasis by secreting angiopoietin1 , VEGF, TGF- $\beta$, FGF-2 and MMPs. Mast cells recruit eosinophil's, $T$ and $B$ cells induce immune response and MDSC accumulation in the tumor microenvironment. These cells activates NF-kB through inflammatory mediators, which increases cell survival, suppress T lymphocytes and natural Killer cell cytotoxic activities [26, 27].

Fibroblasts are recruited to neoplastic cells through various cytokines and growth factors. Carcinoma associated fibroblasts are activated fibroblasts in neoplastic cells and form a myofibroblastic microenvironment of potentially malignant conditions of the oral cavity that promotes cell growth, survival and malignancy. Platelet derived growth factor activates fibroblast proliferation secreted by tumor cells. TGF- $\beta$ produced by macrophages acts as chemoattractant at lower concentration, induces differentiation into 
myofibroblast at higher concentration. Myofibroblast has a role in cancer invasion and degradation of extracellular matrix and basement membrane through proteases such as urokinase activator of plasminogen Mmp's (Matrix mettaloproteases). Myofibroblast express insulin and hepatocytic growth factor, angiogenic growth factors (FGF-2 and VEGF), proinflammatory cytokines (IL-1, IL-6, IL-8 and TNF- $\alpha$ ) induces cell proliferation, survival of cancer cells and angiogenesis, thus enhancing tumor invasion, growth, and metastasis (Table 1) [28, 29].

\section{MYELOID DERIVED SUPPRESSOR CELLS IN CHRONIC INFLAMMATORY MICROENVIRONMENT OF POTENTIALLY MALIGNANT CONDITIONS}

Myeloid derived suppressor cells (MDSC) are heterogeneous population of early myeloid progenitors, which includes immature granulocytes, macrophages and dendritic cells upon chronic inflammation [30, 31]. MDSCs can play a role in tumor development by suppressing innate and $\mathrm{T}$ cell adaptive immune responses and also promote tumor angiogenesis, invasion, and metastasis by producing VEGF, basic fibroblast growth factor(bFGF), hypoxic induced factor(HIF)-1 $\alpha$, TGF- $\beta$ and MMP9 [32]. Inflammatory protein S100A8/A9 produced by MDSCs attracts MDSCs into the tumor site and enhance their immunosuppressive activity but also promote the activation of MAPKs and NF-kB signaling pathways in tumor cells, stimulating tumor growth and metastasis. Activation and expansion of MDSCs is influenced by inflammatory factors released within the tumor microenvironment by tumor and stromal cells are COX2 producing prostaglandins, stem cell factor(SCF), CCL2, GM-CSF, M-CSF, VEGF, CXCL5, calcium binding pro-inflammatory proteins $\mathrm{S} 100 \mathrm{~A} 8$ and S100A9, TNF- $\alpha$ favors the chemotaxis and expansion of immunosuppressive MDSCs by activating STAT-3 transcriptional factor [33]. The main suppressive activity of MDSCs is associated with secretion of arginase-1, iNOS and ROS. iNOS breaks down LArginine into urea and L-ornithine, depleting L-Arginine prevents CD3 generation on T-cells. NO inhibits effector T-cell activation through JAK3 and STAT5 pathways and also abrogate MHC11 molecule

Table 1: Chronic Inflammatory Mediators and their Role in Inflammatory Tumor Microenvironment of Oral Potentially Malignant Conditions [38-41]

\begin{tabular}{|c|c|c|c|}
\hline CYTOKINES & SOURCE & $\begin{array}{l}\text { ACTIVATION OF } \\
\text { TRANSCRIPTIONAL } \\
\text { FACTORS }\end{array}$ & $\begin{array}{l}\text { MECHANISM OF ACTION IN INFLAMMATORY TUMOR } \\
\text { MICROENVIRONMENT }\end{array}$ \\
\hline IL-1 & $\begin{array}{l}\text { TAMS, CAFS, Mast } \\
\text { cells }\end{array}$ & NF-KB & \multirow{2}{*}{$\begin{array}{l}\text { Cell proliferation, Angiogenesis, Resistant to apoptosis, } \\
\text { Cell survival, Immunosuppression, Epithelial to } \\
\text { mesenchymal transition, invasion to metastasis [21] }\end{array}$} \\
\hline TNF- Alpha & $\begin{array}{l}\text { TAMS, CAFS, Mast } \\
\text { cells }\end{array}$ & $\begin{array}{l}\text { HIF - } 1 \alpha \\
\text { NF-KB }\end{array}$ & \\
\hline IL-6 & $\begin{array}{l}\text { TAMS, CAFS, Mast } \\
\text { cells }\end{array}$ & STAT-3 & Cell proliferation, Cell survival [22] \\
\hline IL-8 & TAMS, CAFS & HIF - $1 \alpha$ & Angiogenesis [23] \\
\hline TGF- $\beta$ & TAMS, CAFS, MDSC & & $\begin{array}{l}\text { Immunosuppression, Epithelial to mesenchymal transition, } \\
\text { Metastasis }[23,28,24,25]\end{array}$ \\
\hline IL-17 & Th17 cells & & Angiogenesis, Immunosuppression, Invasion \\
\hline \multicolumn{4}{|l|}{$\begin{array}{l}\text { GROWTH } \\
\text { FACTORS }\end{array}$} \\
\hline FGF & TAMS, CAFS, MDSC & & Angiogenesis $[29,23,31]$ \\
\hline EGF & TAMS & STAT-3 & Cell survival, Cell proliferation, Angiogenesis $[23,30]$ \\
\hline VEGF & TAMS, TAN, MDSC & HIF-1a & Angiogenesis $[32,40,41]$ \\
\hline \multicolumn{4}{|l|}{ ENZYMES } \\
\hline MMPS & TAMS, TANS, MDSC & & Invasion and metastasis $[40,22]$ \\
\hline COX-2 & TAMS & HIF-1 $1 \alpha$ & Angiogenesis, Immunosuppression [23] \\
\hline UPA & TAMS & & Invasion and metastasis [23] \\
\hline
\end{tabular}

Abbreviations-; TAMs; Tumor associated macrophages, CAfs; (Carcinoma associated fibroblasts), MDSC; Myeloid derived suppressor cells, TANs; Tumor associated neutrophils, HIF-1a; Hypoxia inducible factor-1Alfa. 
expression on antigen presenting cells [34, 35]. MDSC mediated immunosuppression is by ROS expression, it is produced by MDSC in response to T-cell interaction or by exposure to cytokines such as TGF- $\beta$, IL-6, IL-10 and GM-CSF [36]. Hydrogen peroxide is a common form of ROS, prevents cytokine secretion and promotes T-cell apoptosis [37]. In the presence of IFN$Y$ and IL-10, MDSC can induce T-reg cells (Regulatory $T$ cell) expansion by interacting with macrophages, NK cells and NKT cells, thus enhance tumor progression [38-40].

Chronic inflammation induced malignant changes in a potentially malignant conditions of the oral cavity such as lichen planus and OSMF is a complex interactions between immune cells and connective tissue stroma in the inflammatory microenvironment. Chronic inflammatory mediators such as chemokine's involved in the recruitment of inflammatory cells, cytokines, growth factors, proteolytic enzymes activate transcriptional factors secreted by inflammatory cells bring about various changes such as cell proliferation, resistant to apoptosis, angiogenesis, epithelial to mesenchymal transition induced invasion and metastasis still need to be understood thoroughly.

Role of chronic inflammatory cells and their mediators in inflammatory microenvironment of potentially malignant disorders of oral cavity such as oral sub mucous fibrosis, oral lichen planus, involved in tumor initiation, promotion, progression of oral cancer and their signaling pathways need to be studied, which is helpful for drug designing and identification of chronic inflammatory biomarkers for tumor prognosis.

\section{CONCLUSION AND FUTURE PROSPECTIVE}

Chronic inflammatory mediators in microenvironment of oral potentially malignant conditions triggers oncopromotion and oncoprogression by various inflammatory mediators such as macrophages, $T$ lymphocytic cells, and carcinoma associated fibroblasts release cytokines, growth factors and proteolytic enzymes. Myeloid derived suppressor cells are immature myeloid cells present in the inflammatory microenvironment as a result of chronic inflammatory mediators, which promotes immunosuppression, escape immune surveillance and tumor progression. In future perspective, identification of suitable inflammatory biomarkers (such as cytokines IL-6, IL-8, COX2) for early detection of malignancy, therapeutic and prognostic purpose. So, that we can intervene at an early stage to prevent from progression into malignancy by suppressing inflammation or inflammatory mediators in particular, microenvironment of oral potentially malignant conditions.

\section{ACKNOWLEDGEMENTS}

The author would like to thank Dr. Naina for her help in the correction of the manuscript.

\section{CONFLICT OF INTEREST STATEMENT}

Authors have declared no conflicts of interest.

\section{FUNDING SOURCES}

This research did not receive any specific grant from funding agencies in the public, commercial, or notfor-profit sectors

\section{ABBREVIATIONS}

$\begin{array}{ll}\text { HGF } & =\text { Hepatic growth factor } \\ \text { VEGF } & =\text { Vascular endothelial growth factor } \\ \text { MMP-9 } & =\text { Matrix mettaloproteinases-9 } \\ \text { COX2 } & =\text { Cyclo-oxygenase2 } \\ \text { INOS } & =\text { Inducible nitric oxide synthase } \\ \text { ROS } & =\text { Reactive oxygen species } \\ \text { PDGF } & =\text { Platelet derived growth factor } \\ \text { EGF } & =\text { Epidermal growth factor } \\ \text { FGF } & =\text { Fibroblast growth factor } \\ \text { TNF-Alfa } & =\text { Tumor necrosis factor-Alfa } \\ \text { IFN-Beta } & =\text { Interferon Beta } \\ \text { IL-10 } & =\text { Interleukin } 10 \\ \text { TGF-Beta } & =\text { Transforming growth factor- Beta } \\ \text { CCL17 } & =\text { CC Chemokine ligand } 17 \\ \text { CCL18 } & =\text { CC Chemokine ligand } 18 \\ \text { CCL22 } & =\text { CC chemokine ligand } 22 \\ \text { PGE2 } & =\text { Prostaglandin E2 } \\ \text { IDO } & =\text { Indole amine } 2,3-\text { dioxygenase }\end{array}$




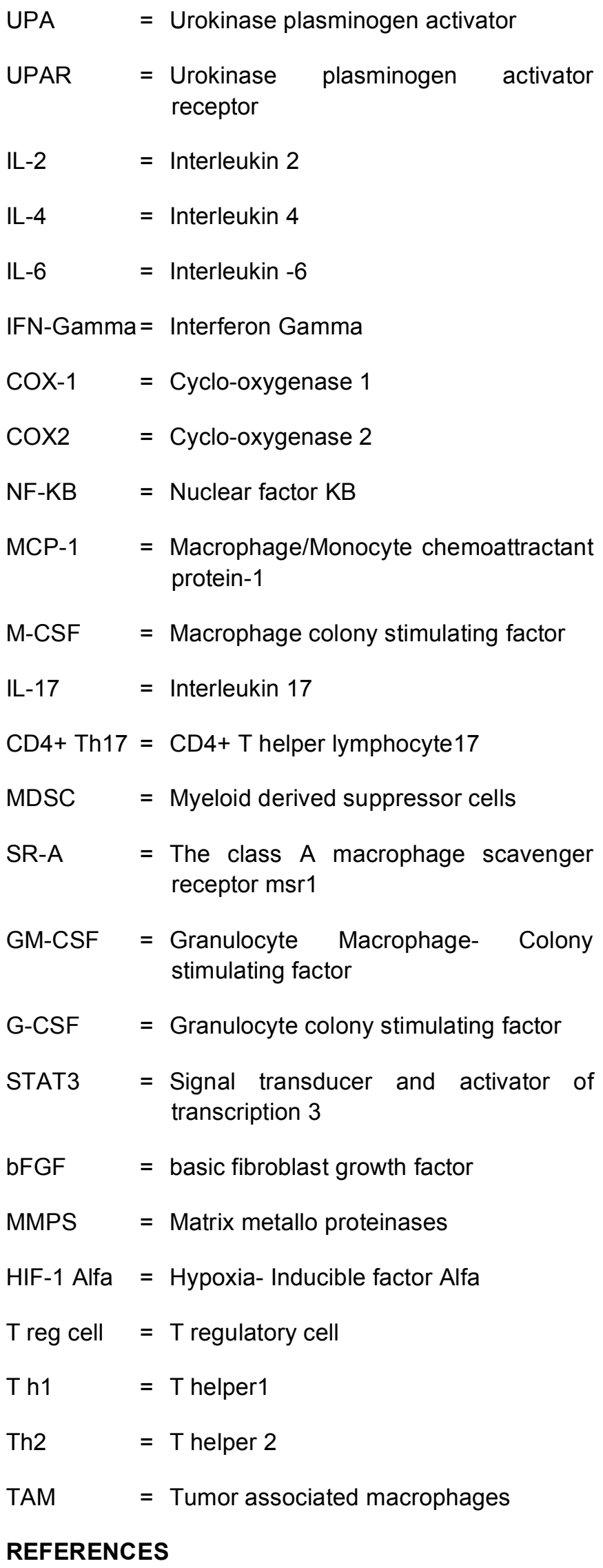

[1] Farhi D, Dupin N. Pathophysiology etiologic factors, and clinical management of oral lichen planus. Part 1. Facts and controversies. Clin Dermatol 2010; 28(1): 100-8. https://doi.org/10.1016/j.clindermatol.2009.03.004

[2] Ismail SB, Kumar SKS, Zain RB. Oral lichen planus and lichenoid reactions; etiopathogenesis, diagnosis, management and malignant transformation. J Oral Sci 2007; 49(2): 89-106.

https://doi.org/10.2334/josnusd.49.89

[3] Parashar P. Oral lichen planus. Otolaryngol Clin North Am 2011; 44(1): 89-107. https://doi.org/10.1016/j.otc.2010.09.004

[4] $\mathrm{Au} \mathrm{J}$, Patel D, Campbell JH. Oral lichen planus. Oral Maxillofac Surg Clin North Am 2013; 25(1): 93-100. https://doi.org/10.1016/j.coms.2012.11.007

[5] Scully C, Beyli M, Ferreiro MC, Ficarra G, Gill Y, Griffiths M, et al. Update on oral lichen planus:Etiopathogenesis and management. Crit Rev Oral Biol Med 1998; 9(1): 86-122. https://doi.org/10.1177/10454411980090010501

[6] Mignogna MD, Fedele S, Lo Russo L, Lo Muzio L, Bucci E. Immune activation and chronic inflammation as the cause of malignancy in oral lichen planus: is there any evidence? Oral Oncol 2004; 40(2): 120-30. https://doi.org/10.1016/j.oraloncology.2003.08.001

[7] Li TJ, Cui J. Cox-2, MMP-7 expression in oral lichen planus and oral squamous cell carcinoma. Asian Pac J Trop Med 2013; 6(8): 640-3.

https://doi.org/10.1016/S1995-7645(13)60110-8

[8] Ekanayaka RP, Tilakaratne WM. Oral submucous fibrosis; Review on mechanisms of pathogenesis and malignant transformation. J Carcinogene Mutagene 2013; 20(2): 2-11.

[9] Colotta F, Allavena P, Sica A, Garlanda C, Mantovani A. Cancer- related inflammation,the seventh hallmark of cancer: links to genetic instability. Carcinogenesis 2009; 30(7): 107381. https://doi.org/10.1093/carcin/bgp127

[10] Legler DF, Bruckner M, Uetz-von Allmen E, Krause $P$ Prostaglandin E2 at a new glance: Novel insights in functional diversity offer therapeutic chances. Int $\mathrm{J}$ Biochem cell Biol 2010; 42(2): 198-201. https://doi.org/10.1016/j.biocel.2009.09.015

[11] Aivaliotis IL, Pateras IS, Papaioannou M, Glytsou C, Kontzoglou K, Johnson EO, et al. How do cytokines trigger genomic instability? J Biomed Biotechnol 2012; 201(2): 536761. https://doi.org/10.1155/2012/536761

[12] Harda A, Sekido N, Akahoshi T, Wada T, Mukaida N, Matsushima K. Essential involvement of interleukin -8 (IL-8) in acute inflammation. Journal of Leukocyte Biology 1994; 56(4): 559-564.

https://doi.org/10.1002/jlb.56.5.559

[13] Xu Q, Wang L, Li H. Mesenchymal stem cells play a potential role in regulating the establishment and maintenance of epithelial -mesenchymal transition in MCF7 human breast cancer cells by paracrine and induced autocrine TGF-beta. International Journal of Oncology 2012; 41(4): 46-58. https://doi.org/10.3892/ijo.2012.1541

[14] Wang $\mathrm{H}, \mathrm{Wu} \mathrm{J}$, Zhang $\mathrm{Y}$. Transforming growth factor beta induced epithelial -mesenchymal transition increases cancer stem -like cells in the PANC-1 cell line. Oncology Letters 2012; 3(1): 229-233.

https://doi.org/10.3892/ol.2011.448

[15] Tindall EA, Severi G, Hoango N. Interleukin-6 promoter variants, prostate cancer risk, and survival. The Prostate 2012; 72(16): 1701-1707. https://doi.org/10.1002/pros.22557

[16] Wang Y, Li LG. Interleukin -6 signaling regulates anchorage -independent growth, proliferation, adhesion and invasion in human ovarian cancer cells. Cytokine 2012; 59(2): 228-236. https://doi.org/10.1016/j.cyto.2012.04.020 
[17] Ben-Neriah Y, Karin M. Inflammation meets cancer, with NFkappaB as the matchmaker. Nature Immunology 2011; 12(7): 715-723. https://doi.org/10.1038/ni.2060

[18] Greten FR, Eckmann L, Greten TF. IKK $\beta$ links inflammation and tumorigenesis in a mouse model of colitis associated cancer. Cell 2004; 118(3): 285-296.

https://doi.org/10.1016/j.cell.2004.07.013

[19] Nehra RB, Riggins AN, Shajahan A, Zwart AC, Crawford Clarke R. BCL2 and CASP8 regulation by $N F-\kappa B$ differentially affect mitochondrial function and cell fate in antiestrogen-sensitive and -resistant breast cancer cells. The FASEB Journal 2010; 24(6): 2040-2055. https://doi.org/10.1096/fj.09-138305

[20] Baldwin AS. Control of oncogenesis and cancer therapy resistance by the transcription factor NF- $\kappa \mathrm{B}$. Journal of Clinical Investigation 2001; 107(3): 241-246. https://doi.org/10.1172/JCl11991

[21] Sheppard K, Kinross KM, Solomon B, Pearson RB, Phillips WA. Targeting PI3 kinase/AKT/mTOR signaling in cancer. Critical Reviews in Oncogenesis 2012; 17(1): 69-95. https://doi.org/10.1615/CritRevOncog.v17.i1.60

[22] Pollard JW. Trophic macrophages in development and disease. Nature Reviews Immunology 2009; 9(6): 259-270. https://doi.org/10.1038/nri2528

[23] Hao NB, Lu MH, Fan YH, Cao YL, Zhang ZR, Yang SM. Macrophages in tumor microenvironments and the progression of tumors. Clinical \& Developmental Immunology 2012; 24(6): 450-461. https://doi.org/10.1155/2012/948098

[24] Bellocq A, Antoine M, Flahault A. Neutrophil alveolitis in bronchio-loalveolar carcinoma: induction by tumor-derived interleukin-8 and relation to clinical outcome. American Journal of Pathology 1998; 152(1): 83-92.

[25] Pekarek LA, Starr BA, Toledano AY, Schreiber H. Inhibition of tumor growth by elimination of granulocytes. The Journal of Experimental Medicine 1995; 18(1): 435-440. https://doi.org/10.1084/jem.181.1.435

[26] Gabrilovich DI, Ostrand-Rosenberg S, Bronte V. Coordinated regulation of myeloid cells by tumours. Nature Reviews Immunology 2012; 12(6): 253-268. https://doi.org/10.1038/nri3175

[27] Houghton AM, Rzymkiewicz DM, Ji H. Neutrophil elastasemediated degradation of IRS-1 accelerates lung tumor growth. Nature Medicine 2010; 16(12): 219-223. https://doi.org/10.1038/nm.2084

[28] Conti P, Castellani ML, Kempuraj D. Role of mast cells in tumor growth. Annals of Clinical and Laboratory Science 2007; 37(4): 315-322.

[29] Huang B, Lei Z, Zhang GM. SCF-mediated mast cell infiltration and activation exacerbate the inflammation and immunosuppression in tumor microenvironment. Blood 2008; 112(4): 1269-1279.

https://doi.org/10.1182/blood-2008-03-147033

[30] Dolcetti L, Peranzoni E, Ugel S, Marigo I, Fernandez Gomez A, Mesa $\mathrm{C}$, et al. Hierarchy of immunosuppressive strength among myeloid-derived suppressor cell subsets is determined by GM-CSF. Eur J Immunol 2010; 40(1): 22-35. https://doi.org/10.1002/eji.200939903

[31] Peranzoni E, Zilio S, Marigol. Myeloid-derived suppressor cell heterogeneity and subset definition. Current Opinion in Immunology 2010; 22(2): 238-244. https://doi.org/10.1016/j.coi.2010.01.021

[32] Greten TF, Manns MP, Korangy F. Myeloid derived suppressor cells in human diseases. International Immuno Pharmacology 2011; 11(7): 802-806. https://doi.org/10.1016/.intimp.2011.01.003

[33] Stairs DB, Bayne L J, Rhoades B. Deletion of p120- catenin results in a tumor microenvironment with inflammation and cancer that establishes it as a tumor suppressor gene. Cancer Cell 2011; 19(4): 470-483. https://doi.org/10.1016/i.ccr.2011.02.007

[34] Bronte V, Serafini P, Mazzoni A, Segal DM, Zanovello P. Larginine metabolism in myeloid cells controls T-lymphocyte functions. Trends Immunol 2003; 24(6): 302-306. https://doi.org/10.1016/S1471-4906(03)00132-7

[35] Bingisser RM, Tilbrook PA, Holt PG, Kees UR. Macrophagederived nitric oxide regulates $T$ cell activation via reversible disruption of the Jak3/STAT5 signaling pathway. JImmunol 1998; 160(12): 5729-5734.

[36] Sauer H, Wartenberg M, Hescheler J. Reactive oxygen species as intracellular messengers during cell growth and differentiation. Cellular Physiology and Biochemistry: International Journal Ofexperimental Cellular Physiology, Biochemistry, and Pharmacology 2001; 11(4): 173-186. https://doi.org/10.1159/000047804

[37] Malmberg KJ, Arulampalam V, Ichihara F, Petersson M, Sek $\mathrm{K}$, Andersson $\mathrm{T}$, et al. Inhibition of activated/memory $(\mathrm{CD} 45 \mathrm{RO}(+)) \mathrm{T}$ cells by oxidative stress associated with block of NF-kappaB activation. J Immunol 2001; 167(5): 2595-2601.

\section{https://doi.org/10.4049/jimmunol.167.5.2595}

[38] Sinha P, Clements VK, Ostrand-Rosenberg S. Interleukin-13regulated M2 macrophages in combination with myeloid suppressor cells block immune surveillance against metastasis. Cancer Res 2005; 65(24): 11743-11751. https://doi.org/10.1158/0008-5472.CAN-05-0045

[39] Shrihari TG, Vasudevan V, Manjunath V, Devaraju D. Potential Co-relation between chronic periodontitis and cancer- An emerging concept. Gulf Journal of Oncology 2016; 1(20): 20-24.

[40] Shrihari TG, Vijeev V, Soundarya K, Deepa Reddy, Manjunath V. Devaraju D. Anti-inflammatory dietary supplements in the chemoprevention of oral cancer. Cancer Research Frontiers 2016; 2(3): 380-395. https://doi.org/10.17980/2016.380

[41] Vishakaha G, Anoop K, Komal S, Gagandeep K. Chronic inflammation and carcinogenesis-Emerging role of chronic inflammatory periodontal disease. Cancer Research Frontiers 2016; 2(2): 200-225.

https://doi.org/10.17980/2016.200 